\title{
Pre-operative Hair Removal: A Literature Review
}

\section{Mohammed Abdullah Hamedan Al Maqbali}

Al-Buraimi Hospital, AL Buraimi, P.O Box: 629, 512, Oman

\begin{abstract}
In pre-operative preparation, has traditionally included the routine removal of body hair from the surgical site. However, there are many studies suggesting not to shaving the incision site. The objective of this review was to determine if shaving compared to non-shaving the surgical site will result in reduced level of infection. Fifteen studies were included in this review; three of them are systematic review. There is inconclusive evidence that hair removal has effects on surgical site infection (SSI). However, there was some evidence that hair removal by clipper and depilation cream was superior to shaving.
\end{abstract}

\author{
Publication History: \\ Received: October 30, 2015 \\ Accepted: January 10, 2016 \\ Published: January 12, 2016

\section{Keywords:} \\ Surgical Site infection, pre- \\ operative preparation, Preoperative \\ Hair Removal, Clipper, Depilation, \\ shaving with razor
}

\section{Introduction}

Surgical site infections (SSIs) occur in the wound after surgical procedure, and have a detrimental effect on patients' treatment. SSI remains a significantly complicated problem in post-operative patients. One study undertaken in the USA reported that approximately $31 \%$ of all healthcare-associated infection among hospitalisation patients was caused by SSIs [1]. Data from the Surveillance of Surgical Infection in NHS Hospitals in England show that SSIs are most frequently reported as nosocomial infections, afflicting $1-10 \%$ of surgical patients.

The aim of this paper is to determine the best practice for preoperative hair removal by reviewing the latest evidence and evaluating the literature on shaving compared with non-shaving methods (for example, clipping) as resulting in lowering the rate of SSIs. The procedure of shaving the operation site with a sharp blade may result in skin surfaces sustaining abrasions that are foci for infection [2]. These abrasions may lead to surgical site infection $[3,4]$. Furthermore, this can result in an increase in the rate of infection, higher treatment costs and prolonged hospitalisation [5]. Despite an improvement in infection control techniques, surgical practice and equipment, SSIs are still a major cause of morbidity and mortality in postoperative patients.

Surgical site infection is defined as infection which occurs within 30 days of surgery, exudes pus, swabs positive for organisms and shows one of the following symptoms: pain, localised swelling, redness or heat [6]. Choosing an appropriate method for removing or not removing hair from the incision site pre-operatively can be essential to avoid harm among surgical patients?

However, a number of studies have exposed patients' experiences of SSI to show the physiological and emotional impact from the patients' perspective. Tunner et al. [7] and Anderson et al. [8] found that patients were suffering from pain and that psychological stress affected patients and their families.

\section{Methodology}

Incidence of infection associated with methods of pre-operative hair removal were researched through the following databases: AMED (Allied and Complementary Medicine), British Nursing Index, CINAHL, Medline, OvidSP and The Cochrane Library. Search terms included: pre-operative hair removal, hair removal, shaving incision site by razor, clipper. The time limit was set to five years initially, but due to the lack of research articles, the period of time was extended to 10 years, from 2001-2011. The primary objective was to establish whether shaving increased the incidence of surgical site infection. The criteria for selection were quantitative research and systematic reviews or meta-analysis.

Fifteen studies met the selection criteria and, of these, three were excluded because they were not proper research articles. Some studies were available only as abstracts. Of all data identified through the search strategy there were 12 studies and three systematic literature reviews included in the review. The studies comprised six RCTs and six different study categories.

\section{Literature review}

A literature review is a critical summary of research studies, frequently concentrating on a specific topic to put a research problem in context [9]. A different view taken by Fain [10] states that it 'involves identification and analysis of relevant publications that contain information pertaining to the research problem' (p.50). The review of literature may lead to the discovery of difficulties that are not already known about the problem. The level of the research in evidence-based practice is called a hierarchy of evidence. The hierarchy of evidence assists in the selection of the best evidence from different types of research in order to indicate validity and trustworthiness [11]. Mantzoukas [12] explained the hierarchy of research evidence. On top of this hierarchy is a systematic review of randomised controlled trials (RCTs). Scanlon [13] makes it clear that least susceptibility of bias in systematic review of randomised controlled trials makes it highest in the hierarchy. The next level is evidence from at least one well-conducted RCT, and the next three levels are researches that are controlled but lack randomisation [14].

A total of six studies were randomised controlled trials [14-18]. The other six studies were not randomised [20-25](Table 1, Table 2 and Table 3).

"Corresponding Author: Dr. Mohammed Abdullah Hamedan Al Maqbali, AlBuraimi Hospital, AL Buraimi, P.O Box: 629, 512, Oman, Tel: 0096825651819 E-mail: mhamedan@hotmail.com

Citation: Al Maqbali MAH (2016) Pre-operative Hair Removal: A Literature Review. Int J Nurs Clin Pract 3: 163. doi: http://dx.doi.org/10.15344/23944978/2016/163

Copyright: (C) 2016 Al Maqbali. This is an open-access article distributed under the terms of the Creative Commons Attribution License, which permits unrestricted use, distribution, and reproduction in any medium, provided the original author and source are credited. 
Citation: Al Maqbali MAH (2016) Pre-operative Hair Removal: A Literature Review. Int J Nurs Clin Pract 3: 163. doi: http://dx.doi.org/10.15344/23944978/2016/163

Page 2 of 6

\begin{tabular}{|c|c|c|c|c|c|c|c|}
\hline & References & Design & $\begin{array}{l}\text { Type of } \\
\text { Participant }\end{array}$ & Sample \& Size & $\begin{array}{l}\text { Outcome } \\
\text { measures }\end{array}$ & Result & Remarks \\
\hline 1 & $\begin{array}{l}\text { Menendezet al. } \\
(2004)\end{array}$ & RCT & $\begin{array}{l}\text { Endoscopic } \\
\text { urological } \\
\text { surgery }\end{array}$ & $\begin{array}{l}\mathrm{N}=127 \\
\text { Excluded }=37 \\
\text { shaved: } 45 \\
\text { notshaved: } 45\end{array}$ & $\begin{array}{l}\text { Urinary } \\
\text { infection }\end{array}$ & $\begin{array}{l}\text { - } \quad \text { No significant difference in } \\
\text { development ofinfection. } \\
10 \text { patients had positive results in } \\
\text { urinary cultures. } \\
\text { - } 5 \text { non-shaved and } 5 \text { shaved. } \\
\text { - Study concluded that hair removal } \\
\text { before surgery should not be done. }\end{array}$ & $\begin{array}{ll}\text { - } & \text { Disposable razor was used for } \\
\text { shaving patients. } \\
\text { - } \\
\text { Patients were followed for one } \\
\text { month. } \\
\text { - Standard protocol of all patients. }\end{array}$ \\
\hline 2 & $\begin{array}{l}\text { Maksimvic et al. } \\
(2008)\end{array}$ & $\begin{array}{l}\text { Cohort } \\
\text { study }\end{array}$ & $\begin{array}{l}\text { Orthopaedic } \\
\text { surgery }\end{array}$ & $\begin{array}{l}\mathrm{N}=157 \\
\text { Excluded }=37 \\
\text { shaved: } 49 \\
\text { notshaved: } 45\end{array}$ & SSI & $\begin{array}{l}\text { - } \quad \text { Nosignificantdifferences. } \\
\text { Developinfection: } \\
\text { Clipper16.6\%(13/78) } \\
\text { Shaved19.2\%(15/78) }\end{array}$ & $\begin{array}{l}\text { - Patients were interviewed by } \\
\text { telephone. } \\
\text { Self-assessment by the patient } \\
\text { and may not be reliable. }\end{array}$ \\
\hline 3 & $\begin{array}{l}\text { Celik and Kara } \\
\text { (2007) }\end{array}$ & RCT & Spinal surgery & $\begin{array}{l}\mathrm{N}=789 \\
\text { Excluded }=47 \\
\text { shaved: } 371 \\
\text { notshaved: } 418\end{array}$ & $\begin{array}{l}\text { Infection } \\
\text { rate }\end{array}$ & $\begin{array}{l}\text { The infection rate in both groups } \\
\text { was statistically significant } \\
(\mathrm{P}=<0.01) \text { and findings strongly } \\
\text { suggested an association between } \\
\text { pre-operative shaving and the } \\
\text { infection rate. } \\
\text { The author strongly recommended } \\
\text { pre-operative shaving as } \\
\text { unnecessary. }\end{array}$ & $\begin{array}{l}\text { - Disposable razor was used for } \\
\text { shaving patients. } \\
\text { - Double blind prospective study. } \\
\text { - Study duration from } 2000 \text { to } \\
2004 .\end{array}$ \\
\hline 4 & Suvera et al. (2013) & RCT & $\begin{array}{l}\text { General } \\
\text { surgery } \\
\text { patients }\end{array}$ & $\begin{array}{l}\mathrm{N}=215 \\
\text { Razor: } 112 \\
\text { Depilation } \\
\text { cream: } 103\end{array}$ & $\begin{array}{l}\text { Infection } \\
\text { rate }\end{array}$ & $\begin{array}{l}\text { - } 18 \text { patients developinfection: } \\
\text { Razor }=15 \\
\text { Depilation cream }=3\end{array}$ & $\begin{array}{l}\text { Only general surgery patients were } \\
\text { included in the study. }\end{array}$ \\
\hline 5 & $\begin{array}{l}\text { Kattipattanapong et } \\
\text { al. (2012) }\end{array}$ & RCT & Ear surgery & $\begin{array}{l}\mathrm{N}=136 \\
\text { shaved:66 } \\
\text { notshaved:70 }\end{array}$ & SSI & $\begin{array}{l}\text { - No significant difference between } \\
\text { the groups. } \\
5 \text { patients had SSIs, } 3 \text { in shaved } \\
\text { group, and } 2 \text { in not shaved group. }\end{array}$ & $\begin{array}{l}\text { The type of randomisation was } \\
\text { mentioned Block system. } \\
\text { The ethical approval mentioned. } \\
\text { The other variable was controlled } \\
\text { by using CDC protocol. }\end{array}$ \\
\hline 6 & Adisaet al. (2011) & RCT & $\begin{array}{l}\text { General } \\
\text { Surgery }\end{array}$ & $\begin{array}{l}\mathrm{N}=165 \\
\text { Razor: } 86 \\
\text { Depilation } \\
\text { cream: } 79\end{array}$ & SSI & $\begin{array}{l}13 \text { developed SSIs: only } 2 \text { in } \\
\text { depilation cream group, and } 11 \text { in } \\
\text { razor group. } \\
\text { Significant difference was found } \\
\text { between shaving by razor and SSIs. }\end{array}$ & \\
\hline
\end{tabular}

\begin{tabular}{|c|c|c|c|c|c|c|c|}
\hline & References & Design & Participant & Sample \& Size & $\begin{array}{l}\text { Outcome } \\
\text { measures }\end{array}$ & Result & Remarks \\
\hline 1 & Trussel et al. (2008) & $\begin{array}{l}\text { Retrospective } \\
\text { chart review }\end{array}$ & $\begin{array}{l}\text { Only CABG } \\
\text { patients }\end{array}$ & $\begin{array}{l}\mathrm{N}=1827 \\
\text { Excluded=not } \\
\text { pre: } 808 \\
\text { post: } 674\end{array}$ & SSI & $\begin{array}{l}\text { In post-intervention } \\
\text { period the use of } \\
\text { shaving decreased } \\
\text { from } 60 \% \text { to } 20 \% \\
(\mathrm{P}=0.00)\end{array}$ & $\begin{array}{l}\text { Patient care path way including } \\
\text { pre-operative antibiotic } \\
\text { administration, tight glucose } \\
\text { control and hair removal by } \\
\text { clipping was implemented. } \\
\text { Incidence of SSI was studied } \\
\text { retrospectively before and after } \\
\text { implementation of patient care } \\
\text { pathway. }\end{array}$ \\
\hline 2 & Grober et al. (2012) & RCT & $\begin{array}{l}\text { Male genitalia } \\
\text { surgery }\end{array}$ & $\begin{array}{l}\mathrm{N}=2015 \\
\text { Clipper: } 107 \\
\text { Razor: } 108\end{array}$ & & $\begin{array}{l}\text { - } 4 \text { patients develop } \\
\text { infection: } \\
2 \text { in clipper group } \\
2 \text { in razor group }\end{array}$ & $\begin{array}{l}\text { Only male patients include in } \\
\text { the study. } \\
\text { The result cannot be generalized } \\
\text { to other surgical specialties. }\end{array}$ \\
\hline
\end{tabular}

\begin{tabular}{|l|l|l|l|l|l|l|l|}
\hline \hline 1 & References & Design & Participant & Sample\&Size & $\begin{array}{l}\text { Outcome } \\
\text { measures }\end{array}$ & Result & Remarks \\
\hline Razaviet al. (2005) & Study & $\begin{array}{l}\text { Abdominal } \\
\text { surgery }\end{array}$ & $\begin{array}{l}\mathrm{N}=802 \\
\text { Excluded=82 } \\
\text { pre:884 } \\
\text { post:802 }\end{array}$ & SSI & - & $\begin{array}{l}\text { Lengthening of } \\
\text { pre-operative } \\
\text { shaving time } \\
\text { was significant at } \\
\mathrm{p}<.0001 .\end{array}$ & $\begin{array}{l}\text {. } \\
\text {. }\end{array}$ \\
\hline
\end{tabular}




\section{Critical Appraisal}

Besides information on the topic, the literature review will be a critical appraisal of the method of conducting studies. Hill and Spittle house [26] suggest that critical appraisal is the process of systematically examining research evidence to assess its validity, results and relevance before using it to inform a decision'.

The studies covered different specialties of surgery. Three studies involved neurosurgery [20,21,22]. Two studies involved general surgery patients $[17,18]$; Celik and Kara $[14]$ worked only on spinal surgery patients and Trussel et al. [23] studied CABG patients. Razavi et al. [24] examined abdominal surgery; Grober et al. [19] male genitalia surgery; Kattipattanapong et al. [16] ear surgery; Maksimvic et al. [25] studied orthopaedic surgery patients; and Menendez et al. [15] studied only endoscopic urological surgery. The findings cannot be generalised toall patients undergoing surgery, but only to those specialties that were involved in this review. The surgical incision of body parts with more hair (for example, urology or neurosurgery) may result in increased SSIs compared with those parts with less hair (for example, abdominal).

Only one study Tang et al., [22] mentioned about the blinding, that one researcher is blinded the intervention, which means that the researcher was not aware of whether the groups were shaved or not. Other studies did not give any information as to whether adequate blinding had been achieved. Blinding is intended to reduce bias and protect the sequence after allocation [27].

Six studies provided information about the ethical approval that had been obtained $[14,16,17,19,23,25]$. The other six studies did not report the ethical approval, whether obtained or not. It is important to mention in the manuscripts that ethical approval is taken or not. Research on human participants should be submitted to independent ethical review boards for approval according to the Declaration of Helsinki [28]. Ethical approval is required to minimise risk and it confirms that the participants have informed consent, confidentiality, anonymity and protection from harm [29]. The ethical committee will also discuss the design of the study and methodology of analysis [30].

Seven studies specify where the hair removal took place. Four stated that shaving was carried out in the operating theatre $[17,19,20,23$,], and two on the ward $[16,18]$. Other studies did not give information about where the hair removal took place.

The United States Centers for Disease Control and Prevention (CDC) have published a recommendation for prevention of surgical site infection. It provides strategies that can reduce SSIs, for example: patient characteristic, diabetes, nicotine, pre-operative issue, antiseptic showing, patient's skin preparation, antimicrobial prophylaxis, postoperative issues, incision care, and discharge planning. Alexander et al. [8]) suggest that the CDC recommendation is a suitable standard for monitoring and identifying SSIs. Four studies used the CDC recommendation to control the other variables with hair removal $[16,20,23,25]$. The other 12 studies did not give information about how they controlled the other variables.

According to CDC, the time period for wound assessment postoperatively should be 30 days. The follow-up period to assess the wound infection varied between studies. However, most of the studies were assessing for more than 30 days, except Tanner et al. [31], who assessed at two weeks. Two studies did not provide any information about the time of wound assessment $[14,21]$. The time of assessing the wound is important because if infection occurs within this period of time, not assessing it means that some of the patients with SSIs will be missed.

The time of hair removal was specified by nine studies. Five studies stated that hair removal was on the morning of surgery $[17,18,21,22,23]$, while in another two studies it was carried out after the induction [19,20]. In Kattipattanapong et al. [16] it was performed the day before surgery. Razavi et al. [24] were more specific about the time of hair removal. To minimise the risk of SSI, the hair removal should take place less than two hours before surgery, or preferably just before surgery [6].

\section{To shave or not to shave}

Celik and Kara [14] in their randomised controlled trial recommended that pre-operative hair removal is unnecessary. The study includes 789 patients divided into two groups: the shaved group with 371 patients and the unshaved group with 418 patients. The sample size was large and they controlled the external validities such as age, sex and smoking, and internal validities such as duration of anaesthesia and receiving the same dose of antibiotic. They excluded 47 patients from the shaved group for the reason that they did not follow up after discharge. Post-operative infection developed in four patients in the shaved group and in one patient in the non-shaved group $(\mathrm{P}<0.01)$. The study concluded that shaving of the incision site pre-operatively may increase the rate of infection. Conversely, Menendez et al. [15] conducted randomised controlled trials of urological surgery patients by studying whether post-operative urine cultures were negative or positive. The sample size was 127 patients and 37 patients were excluded. The sample size in both groups was only approximately 45 . The ratio of infection in non-shaved to shaved was 5:5. This rate is slightly high because the sample size was small. The study controlled the characteristic of the two groups by checking for homogeneity. The study suggested that shaving urological patients does not affect the incidence of urinary infection.

Maksimvic et al. [25] conducted a prospective cohort study to identify the incidence rate and risk factors for SSIs in orthopaedic wards. The assessment result was that 63 out of 277 patient's developed infection. The high infection rate may be due to the fact that the method of hair removal in this study was by razor.

A randomed controlled trial conduct by Kattipattanapong et al. [16] compared the rate of surgical site infection between shaved and not shaved. A group of 136 patients was divided into two. Sixty-six patients had their hair removed by razor and 70 patients were without hair removal. Only five patients had post-surgical site infection; three were in the hair removal group, and two were in the group without hair removal. All five patients had undergone mastoidectomy surgery. The study concluded that there was no significant difference in surgical site infection between the two groups (with and without hair removal).

Numerous research studies on neurosurgical patients have concentrated on skull shaving [20-22] and they recommend that hair removal from the skull is not necessary.

Gil et al. [20] completed a retrospective study of 175 patients who were not shaved. The data were collected over seven years, from 1994 to 2001 . The aim of the study was to evaluate surgical wound 
infection rates in patients undergoing skull base surgery without hair removal. Overall surgical site infection was $1.1 \%$ (2 of 175). They compared 17 studies from 1985 to 2000 involving variable sample sizes. In these studies all patients were shaved. The wound infection rate varied from $1.5 \%$ to $30 \%$. However, other variables for infection were not controlled. They also observed that by using the hair sparing procedure, the self-image and psychological conditions were better for rapid rehabilitation. There were no inclusion criteria among the participants and criteria of sample selection were not defined here, so the validity of the sample is questionable. Polit and Beck [32] suggest that inclusion criteria used in the sample have implications for both the interpretation of the result and the generalisation of the findings.

Miyagi et al. [21] conducted a retrospective analysis of unshaved patients undergoing an implantation procedure. The study comprised two groups: 39 shaved and 182 unshaved, a total of 221 participants (they excluded three patients). There is a big difference between the sample sizes in the two groups. The internal validity of the groups was very low because the groups were not of equivalent size [33] Therefore bias in selection cannot be excluded. Moreover, other variables of participants are not compared in this study. Two cases were infected: one (1.6\%) in the shaved group and one $(0.8 \%)$ in the unshaved group. Nonetheless, the researchers argue that leaving the hair is safer than hair removal.

Tang et al. [22] carried out a prospective non-randomised study with 100 participants, 65 in the shaved group and 35 in the nonshaved. Patients with evidence of existing infection were excluded. The sample sizes were uneven. Other variables in the groups were controlled: duration of operation, cleaning solutions, antibiotics used and surgeon grade. The rate of infection was two in each group and the results were not statistically significant $(\mathrm{p}=0.10)$.

All three studies on neurosurgical patients concentrated on skull shaving $[20,21,22]$ recommended that hair removal from the skull is not necessary. In addition, Celik and Kara [14] and Maksimvic et al. [25] found that hair removal by razor may increase the rate of infection. Kattipattanapong et al. [16] and Menendez et al. [15] suggested that hair removal in urological patients does not influence infection. The studies' participants were varied; hence it cannot be generalised to all surgical patients.

\section{Clipping versus Shaving}

Trussell et al. [23] have shown that clipping compared with shaving reduces infection after surgery from $60 \%$ to $20 \%(\mathrm{p}=0.001)$. This retrospective study was conducted over a period of 39 months with a total of 1,827 CABG procedures in two groups. Each group had approximately 800 patients. The sample is large and the base line characteristic of patients such as age, blood sugar, gender, etc. in each group was considered. The reference point for this study was the date of implementing the Center for Disease Control (CDC) protocol. During the study care was taken to compare the groups on an equal basis; for example, when shaving was compared with clipping it was seen that other variables such as obesity or smoking were under control.

Grober et al. [19] conducted a randomised trial to investigate the infection rate after using a clipper or a razor. The study includes 215 patients undergoing male genitalia surgery (108 in the razor group and 107 in the clipper group). The result of the study was that four patients developed SSIs during the follow up; two of whom were in the clipper group and two of whom were in the razor group. There was no significant difference between the two groups in infection rate.

\section{Depilation cream versus Shaving}

Razavi et al. [24] showed statistical significance in the time elapsed between shaving and operation site incisions in reducing surgical site infection, with $\mathrm{p}<0.001$. This was a study to assess incidence and risk factors associated with abdominal SSI. The sample consisted of 802 patients divided intotwogroups; one of the groups was shaved one hour before surgery and the other, 12 hours before. They excluded 82 patients and indicated the reason for exclusion. They collected data by pre-operative and post-operative interview, by telephone for 30days. The methodology of data collection could be considered inappropriate because it depended on the patients' experience alone. The variation in the reporting of data will affect the reliability of measurement tools [33]. A reliable measurement is consistency of the sample attribute [9].

\section{Systematic Review}

Kjonniksen et al. [34] published a systematic review on preoperative hair removal and SSI. The period of review covered up to 1999 and the review included nine RCTs and 12 observational studies. The authors did not describe the criteria of selection of studies they used and did not assess the quality and details of each individual study.

In comparing Kjonniksen's study with that of the systematic study performed by Tanner et al. [35] on pre-operative hair removal to reduce surgical site infection, the period covered was from 1966 to 2005 , and consisted of eleven RCTs involving 5,030 people. The studies were from 1971 to 1992, when methodology was not the same as it is now. Since1992, research methodology and other facilities available for research have changed remarkably.

Both the above-mentioned reviews agree that there is insufficient evidence to support pre-operative hair removal related to a reduced infection rate. They recommend that if it is necessary to remove hair, both clipping and depilatory cream resulted in fewer SSIs than shaving with a razor.

Another systematic review of randomised controlled trails was performed by Niel-Weise et al. [36]. They reviewed four RCTs up to 2005 and the methodology of each component of the RCTs was investigated. There was inconclusive evidence that hair removal has an effect on SSI. In addition, the influence of time of hair removal and time of operation was also inconclusive. However, there was some evidence that hair removal by clipper was superior to shaving (Table 4).

\section{Summary of Literature Review}

The review is to identify the appropriate method of hair removal before elective surgery by comparing depilation, clipping and shaving with a razor as preventing SSIs. Seven studies compare hair removal by razor with not shaving. Five studies recommend not to shave patients pre-operatively, and show an association between shaving by razor and rate of infection [20]; Miyagi et al. [21], Tang et al. [22]; Celik and Kara [14], and Maskimovic et al. [25]. Other studies fail to show statistically significant differences in shaving or not shaving before surgery that influence SSIs Kattipattanapong et al. [16] and Menendez et al. [15], but recommend avoidance of shaving if possible. 


\begin{tabular}{|c|c|c|c|c|}
\hline & References & $\begin{array}{l}\text { No. of articles } \\
\text { Studied }\end{array}$ & No. of RCTs & Result \\
\hline 1 & $\begin{array}{l}\text { Kjonniksen et } \\
\text { al.(2002) }\end{array}$ & 20 & 8 & $\begin{array}{l}\text { - It is not strongly documented that hair removal results in a higher frequency of SSI than nohair } \\
\text { removal. } \\
\text { Several randomised and observational studies with controls show that either wet or dry shaving the } \\
\text { evening before the procedure results in a significantly higher infection rate than depilatory or electric } \\
\text { clipping } \\
\text { There is no convincing difference in the incidence of postoperative SSIs between electric clippings, } \\
\text { depilatory cream or no hair removal. } \\
\text { - Hair removal with clippers should be performed as closed as possible to the time of the procedure. }\end{array}$ \\
\hline 2 & $\begin{array}{l}\text { Niel-Weise et al. } \\
(2005)\end{array}$ & 4 & 4 & $\begin{array}{l}\text { Data from the results off our trials comparing different hair removal policies were sparse. Evidence } \\
\text { tha thair removal has any effect is inconclusive. When hair removal is considered necessary, evidence } \\
\text { about when hair should be removed is inconclusive. There was some evidence that hair removal by } \\
\text { clipper is superior to hair removal by razor. }\end{array}$ \\
\hline 3 & Tanner et al. (2009) & 11 & 11 & $\begin{array}{l}\text { - There view finds insufficient evidence of an effect of preoperative hair removal on rates of SSIs and of } \\
\text { the relative effects of shaving and depilatory cream. } \\
\text { - There is no research comparing hair removal using clippers with nohair removal. } \\
\text { If it is necessary to remove hair then both clipping and depilatory cream result in fewer SSI than } \\
\text { shaving with a razor. Not rial shave compared clipping with depilatory cream. }\end{array}$ \\
\hline
\end{tabular}

Two studies investigate the infection rate after using a clipper or a razor. Trussell et al. [23] support the claim that a clipper can reduce SSIs more than a razor. However, Grober et al. [19] cannot find enough evidence to support clipper or razor in pre-operative hair removal related to a reduced infection rate.

Two studies compare depilation creams and shaving, Adisa et al. [17] found that hair removal by razor is significantly associated with post-operative wound infection, whereas Suvera et al. [18] did not find any difference between removal of hair pre-operatively by razor ordepilation creamand surgical site infection. Developed countries have the financial resources to maintain aclean environment in the operating room with a high standard of facilities. In non-developed countries it is possible, for example, that the ventilation system is insufficient or that cleaning of the operating room is inadequate. This could be one of the causes for increases in the SSI rate from one study to another.

Only one study [24] identify the time of hair removal as having statistical significance in the time elapsed between shaving and operation site incisions in reducing surgical site infection.

From all of the systematic reviews there is inconclusive evidence to support the effect of hair removal on SSI. However, there is a suggestion that hair removal by clipping is better than using a razor. The evidence so far supports the view that use of clippers instead of a razor to remove hair from surgical sites may reduce SSI.

\section{Discussion}

The practice of pre-operative hair removal has a long history, and it was previously thought to prevent infection. Several studies question whether hair removal may be harmful to patients and may increase the infection rate [14]. Shaving can cause small skin surfaces to sustain abrasions that multiply microorganisms. Those microorganisms can enter the incision site, leading to infection [37]. The CDC (2008) has attempted to reduce complications following surgery and specifically SSIs by controlling the measurement of pre-operative, intra-operative, and post-operative infection; however, most of these measures need further evidence.

The cost of treating patients with SSI is very high; for example, in the United States, nearly two million patients acquire an infection; approximately 90,000 of these patients die [38]. Infections cause prolonged hospitalisation and increase the cost of treatment for the patient and government [5]. Clippers not only have a clinical advantage but they are also cost effective. In one study, it was found that the cost of treating each infected patient was $£ 10,523$ and in addition an extra five-month rehabilitation programme cost $£ 5,200$ [37].

\section{Conclusion}

In summary, the aim of this review is to identify the best evidence on pre-operative shaving to reduce SSIs. Despite some limitations of the studies in this review, it is suggested that when it is necessary to remove hair pre-operatively, it should be removed immediately before surgery, and preferably by clipper or depilation cream. Avoid using a razor pre-operatively in order to reduce SSIs.

A further research study should consist of a robust methodology with a large sample size and different types of surgery. The CDC (2008) assessment method for the identification of SSIs and consideration of the variables affecting their occurrence should be followed. In addition; it is recommended that a future study reports on the length of stay and any complications of infected patients.

To conclude the result of this study, it has been shown that preoperative shaving with razors is not necessary and that there are other methods that can be used for hair removal. The rate of infection is reduced by using clippers or depilation cream.

\section{Competing Interests}

The authors have no competing interests with the work presented in this manuscript.

\section{References}

1. Magill S, Koh HC, Renwick A, Vella M (2012) Salmonellosis as a differential diagnosis. BMJ Case Rep 2012.

2. Owens CD, Stoessel K (2008) Surgical site infections: epidemiology, microbiology and prevention. J Hosp Infect 70 Suppl 2: 3-10.

3. Griffin FA (2005) Best-practice protocols: Preventing surgical site infection Nurs Manage 36: 20, 22-26.

4. Eagye KJ, Nicolau DP (2009) Deep and organ/space infections in patients undergoing elective colorectal surgery: incidence and impact on hospital length of stay and costs. Am J Surg 198: 359-367.

5. Broex EC, van Asselt AD, Bruggeman CA, van Tiel FH (2009) Surgical site infections: how high are the costs? J Hosp Infect 72: 193-201. 
Citation: Al Maqbali MAH (2016) Pre-operative Hair Removal: A Literature Review. Int J Nurs Clin Pract 3: 163. doi: http://dx.doi.org/10.15344/2394$4978 / 2016 / 163$

Page 6 of 6

6. Mangram AJ, Horan TC, Pearson ML, Silver LC, Jarvis WR (1999) Guideline for Prevention of Surgical Site Infection 1999. Infect Control Hosp Epidemiol 20: 247-278

7. Tanner J, Norrie P, Melen K (2011) Preoperative hair removal to reduce surgical site infection. Cochrane Database Syst Rev 11: CD004122.

8. Alexander JW, Solomkin JS, Edwards MJ (2011) Updated recommendations for control of surgical site infections. Ann Surg 253: 1082-1093.

9. Polit DF and Beck CT (2003) Nursing Research Principle and Methods (7th edn). Philadelphia: Lippincott Williams \&Wilkins.

10. Fain J (2003) Reading, understanding, and applying nursing research (2nded.edn) Philadelphia: F. A Davis Company.

11. Evans D (2003) Hierarchy of evidence: a framework for ranking evidence evaluating healthcare interventions. J Clin Nurs 12: 77-84.

12. Mantzoukas S (2007) A review of evidence-based practice, nursing research and reflection: leveling the hierarchy. Journal of clinical Nursing 17: $214-233$

13. Scanlon A (2006) Critical appraisal of systematic for nursing practice Australasian Journal of Neuroscience 18: 8-14.

14. Celik SE, Kara A (2007) Does shaving the incision site increase the infection rate after spinal surgery? Spine (Phila Pa 1976) 32: 1575-1577.

15. Menendez V, Calan J A, Elia M, Collado A, Llorens F, et al. (2004) Is It Necessary to Shave the Public and Genital Regions of Patients Undergoing Endoscopic Urological Surgical? Infect Control Hosp Epidemiol 25: 519 521.

16. Kattipattanapong W, Isaradisaikul S, Hanprasertpong C (2013) Surgica site infections in ear surgery: hair removal effect; a preliminary, randomized trial study. Otolaryngol Head Neck Surg 148: 469-474.

17. Adisa AO, Lawal OO, Adejuyigbe O (2011) Evaluation of two methods of preoperative hair removal and their relationship to postoperative wound infection. J Infect Dev Ctries 5: 717-722.

18. Suvera M, Vyas P, Patel M, Varghese V, Ahmed, et al. (2013) Two methods of pre-operative hair removal and their effect on post operative period. Int $J$ Med Sci Public Health 2: 885-888.

19. Grober ED, Domes T, Fanipour M, Copp JE (2013) Preoperative hair removal on the male genitalia: clippers vs. razors. J Sex Med 10: 589-594.

20. Gil Z, Cohen JT, Spektor S, Fliss DM (2003) The role of hair shaving in skull base surgery. Otolaryngol Head Neck Surg 128: 43-47.

21. Miyagi Y, Shima F, Ishido K (2002) Implantation of deep brain stimulation electrodes in unshaved patients. Technical note. J Neurosurg 97: 14761478.

22. Tang K, Yeh JS, Sgouros S (2001) The Influence of hair shave on the infection rate in neurosurgery. A prospective study. Pediatr Neurosurg 35 : 13-17.

23. Trussel J, Gerkin R, Coates B, Brandenberger J, Tibi P, et al. (2008) Impact of a patient care pathway protocol on surgical site infection rates in cardiothoracic surgery patients. The American Journal of Surgery196: 883-889.

24. Razavi SM, Ibrahimpoor M, Sabouri Kashani A, Jafarian A (2005) Abdominal surgical site infections: incidence and risk factors at an Iranian teaching hospital. BMC Surg 5: 2 .

25. Maksimovic J, Markovic-Denic L, Bumbasirevic M, Marinkovic J, Vlajinac $H$ (2008) Surgical site infections in orthopedic patients: prospective cohort study. Croat Med J 49: 58-65

26. Hill A, Spittlehouse C (2001) What is critical appraisal?

27. Schulz KF, Chalmers I, Altman DG (2002) The landscape and lexicon of blinding in randomized trials. Ann Intern Med 136: 254-259.

28. World Medical Association (2008) Declaration of Helsinki: Ethical Principles for Medical Research Involving Human Subjects.

29. Latimer J (eds.) (2003) Advanced Qualitative Research for Nursing. Oxford: Blackwell Science.
30. Martin CR, Thompson DR (2000) Design and Analysis of Clinical Nursing Research Studies. London: Routledge.

31. Tanner J, Khan D (2008) Surgical site infection, preoperative body washing and hair removal. J Perioper Pract 18: 232, 237-243.

32. Polit D F and Beck C T (2006) Essentials of Nursing Research Methods Appraisal, and Utilization (6th edn).Philadelphia: A Wolter Kluwer Company.

33. Morgan GA, Gliner JA, Harmon RJ (2006) Understanding and Evaluating Research in Applied and Clinical Settings. Mahwah: Lawrence Erlbaum Associates, Publishers.

34. Kjønniksen I, Andersen BM, Søndenaa VG, Segadal L (2002) Preoperative hair removal--a systematic literature review. AORN J 75: 928-938, 940.

35. Tanner J, Khan D, Aplin C, Ball J, Thomas M, et al. (2009) Post-discharge surveillance to identify colorectal surgical site infection rates and related costs. J Hosp Infect 72: 243-250.

36. Niël-Weise BS, Wille JC, van den Broek PJ (2005) Hair removal policies in clean surgery: systematic review of randomized, controlled trials. Infect Control Hosp Epidemiol 26: 923-928.

37. Tanner J (2009) Patietns skin preparation. In edits Hughes S, Mardell A. Oxford handbook of preoperative practice. Oxford: Oxford University Press

38. Odom-Forren J (2004) Watch that incision! Nurs Manage 35 Suppl OR Insider: 16-21. 